\title{
Introduction
}

Listeners have been shown to adapt rapidly to new accents in their native language (Maye, 2003; Clarke \& Garrett, 2004). These previous studies used accented running speech or single sentences. In the present study, Englishspeaking listeners were exposed to alist of lexical items in which " wont vowels were lowered (e.g., "witch" beca. "witch" became "wech") but vols were not (e.g., moon). These items were heard in isolated form with visual referents. This builds on previous work, lending itself well to eye-tracking. Also, the accent presented in this study affects only a portion of vowel space, similar to a regional dialect. Generalizations to novel items and

Materials

.64 monosyllabic pictureable nouns. Each noun was recorded twice by male native speaker of Standard American English: Once as SAE, American English: Once as once with a shifted vowel as
on depicted below (Accented English, $\mathrm{AE})$.

-Sounds were normalized for amplitude.

-Pictures were selected from publicly available clipart collection.

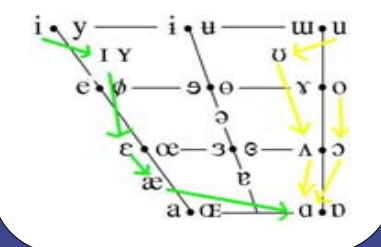

\section{Return of the weckud wetch: Rapid adaptation to a new accent}

$4 \mathrm{pSC} 16$

Neil P. Bardhan, Richard N. Aslin, and Michael K. Tanenhaus

Department of Brain and Cognitive Sciences, University of Rochester

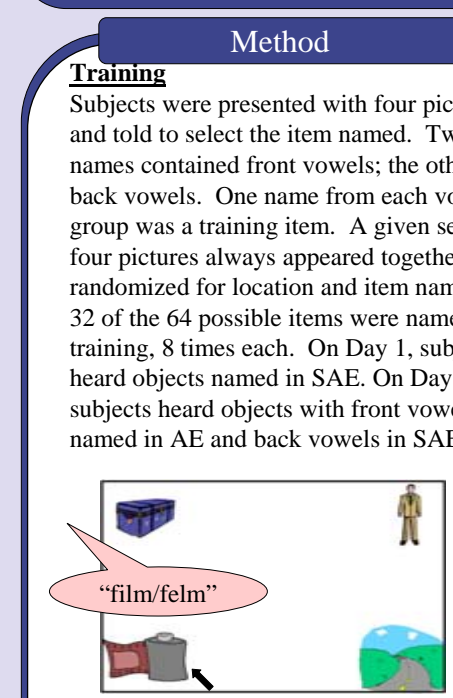

Test:

•Both days, lexical decision on all 128 items (4 repetitions each) in the absence of pictures

\section{Predictions}

-Visual referents will aid dialect learnin •"Word" responses will increase across sessions

- A familiarity effect will yield a greater increase in "word" responses for trained vs. untrained items

-Learned shift in vowels will not transfer across vowel space (front to back)

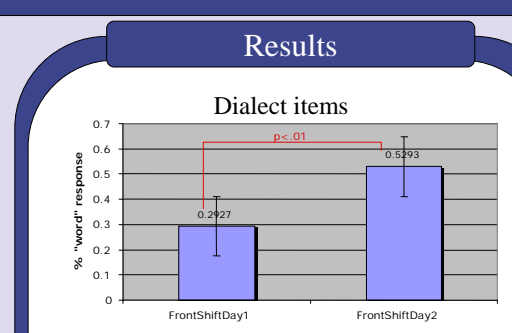

Shifted, front-vowel items were reported as "words" more often on Day 2 than Day 1.

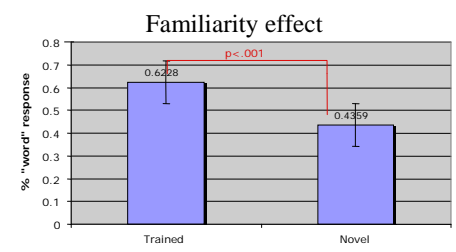

On Day 2, familiar shifted, front-vowel items were reported as "words" more often than

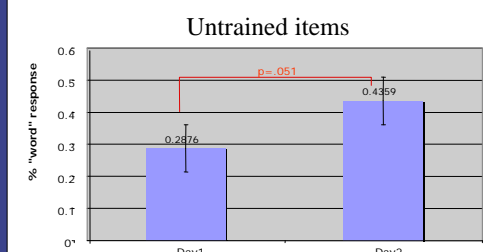

On Day 2, dialect items not heard in training were slightly more likely to be reported as words" than on Day 1.

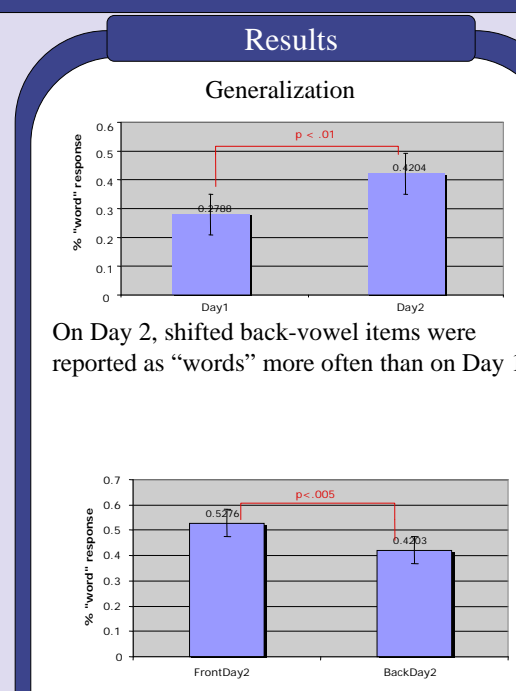

On Day 2, shifted front-vowel items were reported as "words" more often than shifted back-vowel items.

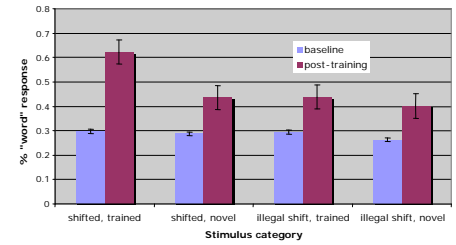

"Word" responses increased on Day 2 in all categories, with the largest change in shifted, trained words novel (untrained) shifted items.

-A training phase in which pictures are paired with isolated sound forms alters what subjects consider to be acceptable forms of English words.

- Familiar (trained) items in a new dialect are better learned as words than unfamiliar (untrained) items.

-Learning a new dialect does generalize to untrained items.

-Unlike Maye, et al.(2003), we found that words with lowered back-vowels (unattested in the training phase) were also more likely to be accepted as words.

-However, there was specificity of dialect training because the

likelihood of accepting a shifted vowel as a word was greater for front vowels (trained) than for back-vowels (untrained).

Resynthesized speech items

-Natural vowel (e.g. chain) shifts - Speaker specificity

Phonologically conditioned shifts

-Eye-tracking

Neuroimaging

\section{References}

Maye, Aslin, and Tanenhaus, "In search of the weckud
wetch: Online adaptatitop to onference on Sentence Processing, Cambridge, MA

Clarke and Garrett, "Rapid adaptation to foreign-
accented English," JASA 116, 3647-3658 (2004)

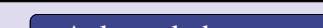

Acknowledgements Acknowledgements
We would like to thank Dana Subik, Sarah Creel, and Meghan Clayards for their technical assistance in this
study. Work was supported by NIH 5R01DC005071-05 sudy. Work was supported by
nd NIH 5T32DC000035-12. 